\section{Perceived urgency and the anaesthetist: responses to common operating room monitor alarms}

G. Allen Finley MD FRCPC, Annabel J. Cohen PhD

\begin{abstract}
Increasing numbers and varieties of electronic monitors are used in hospital operating rooms. Many of these are equipped with auditory alarms which are loud, insistent, or irritating, and thus are frequently disabled by the anaestherist. This study was planned to evaluate two components of auditory alarm design which may influence the usefulness of the alarm: the perceived urgency of the auditory signal and its correlation with the urgency of the corresponding clinical situation. We also assessed the ability of practising anaesthetists to identify the monitor or condition responsible for the alarm. Sixty-four anaesthetists attending a national conference assessed ten common operating room alarm sounds for perceived urgency. Results were compared with the urgency of the corresponding clinical situation as determined by 12 senior anaesthetists. Discrepancies between the clinical and perceived urgencies of several monitor alarms were found, and there was no correlation benveen the nvo measures. The subjects were also tested for their ability to identify the alarm sounds correctly. The overall correct identification rate was $33 \%$, and only two monitors were correctly identified by more than 50\% of the subjects. The results of this study have implications for design and use of auditory alarms in hospitals and suggest the need for further research.
\end{abstract}

On utilise de plus en plus divers moniteurs électroniques en salle d'opération. Plusieurs d'entre eux sont pourvus d'alarmes

\section{Key words}

EQUIPMENT: alarms;

MONITORING: blood pressure, carbon dioxide, electrocardiogram, electrocautery, infusion pump, ventilation.

From the Departments of Anaesthesia and Psychology, Dalhousie University.

Address correspondence to: Dr. G.A. Finley, Department of Anaesthesia, Izaak Walton Killam Children's Hospital, Halifax, NS B3J 3G9.

Accepted for publication 3rd June, 1991. sonores puissantes, persistantes ou ennuyeuses si bien, que l'anesthésiste les mets souvent hors fonction. Nous avons évalué deux aspects de ces alarmes qui peuvent influencer leur utilité soit: l'urgence perçue d̀ l'écoute de l'alarme et sa corrélation avec le degré d' urgence de la situation clinique correspondante. Nous avons aussi demandé aux anesthésistes d'identifier le moniteur ou le problème à la source de l'alarme sonore. Soixante-quatre anesthésistes en congrès se sont prêtés à notre étude et douze anesthésistes seniors ont agi comme arbitre du degré d'urgence clinique. Nous $n^{\prime}$ avons trouvé aucune corrélation entre le degré d' urgence de l'alarme tel que perçu par les anesthésistes et l'urgence « vraie » du problème clinique. De plus, les anesthésistes n' identifiaient l' alarme en cause que dans $33 \%$ des cas et le taux de reconnaissance ne dépassait 50\% que pour deux moniteurs. Cette étude devrait être prise en considération dans le développement et l'utilisation des alarmes sonores à l'hôpital.

Automated monitors are used in a number of environments, including power plant control rooms, aircraft flightdecks, air traffic control, and hospital operating rooms and intensive care units. The success of these monitors depends on the extent to which they alert or attract the attention of the human operator. Most monitors deliver alarms when the measured variable crosses a preset limit or threshold, and many operators have difficulty in identifying and assigning a priority to this type of alarm.' Incidents have even occurred where highly trained flight crews have apparently ignored auditory warnings of critical importance while investigating other relatively minor malfunctions. Recently, an increase in the number and variety of electronic operating room monitors has resulted in a similar increase in the number of auditory alarm signals to which a rapid and specific response is required. Many of these alarms are loud, irritating, startling, and confusing. These aversive qualities of alarm sounds, combined with a high false alarm rate, may result in intentional disabling of the alarm by the operator. ${ }^{2-4}$ 
TABLE I Monitors tested

\begin{tabular}{lll}
\hline Monitor & Manufacturer model & Description \\
\hline Oxygen analyzer A & $\begin{array}{l}\text { North American Dräger } \\
\text { (Narkomed 2A) }\end{array}$ & Intermittent, 2 tones, "musical" \\
Oxygen analyzer B & Critikon Oxychek & Interrupted, high-pitched \\
Oximeter & Nellcor N-100 pulse oximeter & Low pitched "beep" with pulse \\
Capnometer & Datex/Puritan Bennett & Continuous complex tone-"buzz" \\
BP machine & Dinamap Vital Signs 1846 5X & Burst of 12 rapid high-pitched "beeps" \\
Ventilator disconnect & Norh American Dräger & Continuous, high-pitched, with ventilator sound \\
& (Narkomed 2A) & \\
Oxygen supply failure & North American Dräger & High-pitched mechanical whistle, decays in pitch and amplitude \\
& (Narkomed 2A) & \\
Electrocautery & Valleylab SSE3B & Continuous high-pitched "beeps" \\
ECG & Vivatek S14 & Interrupted, high-pitched \\
Infusion pump & IMED Corp. Model 960 & Intermittent, high-pitched, "musical" \\
& Volumetric & \\
\hline
\end{tabular}

One component of the interaction between human and machine may be described as perceived urgency, which is the importance attributed to the alarm based primarily on its acoustic properties. A major anaesthesia conference in our city provided the opportunity to study the responses of anaesthetists to some common, commercially available monitor alarms and to attempt to correlate the perceived urgency of these alarms with the "clinical urgency" of the corresponding event. In addition, we evaluated the ability of anaesthetists to identify the monitors involved.

\section{Method}

Warning signals from ten hospital monitors (Table I) in an unused operating room were recorded with a Marantz Professional stereo cassette recorder PMO360 3-head system using a Sony ECM-150T electret condenser microphone. Each monitor was turned on and the microphone was placed close to the speaker.

Three test tapes were constructed by re-recording from the master tape using the Marantz recorder connected in stereo to a Denon PMA-500V Amplifier and Yamaha Stereo Cassette Deck K-720. Each contained two different sequences of alarm signals recorded from the ten monitors. A female voice announced the trial number prior to the warning signal. The duration of each of the ten presentations was 12 seconds with an inter-stimulus interval of five seconds. The time for each set of ten warnings was approximately $2.5 \mathrm{~min}$.

Temporal and spectral representations of these signals (Figure) were generated from one of the test tapes using the sound digitizer MacRecorder ${ }^{\text {tro }}$ and the editing program SoundEdit (Farallon Computing Inc., 2150 Kittredge St., Berkeley CA 94704) on a Macintosh II computer.

Testing took place in a relatively quiet area near the registration desk of the Halifax World Trade and Conven- tion Centre on two days during an annual meeting of the Canadian Anaesthetists' Society. Three playback audio cassette tape recorders (two Marantz and one Yamaha as described above) with high-quality stereo headphones (Radio Shack) were used, allowing up to three subjects to be tested simultaneously. Notices were distributed to people attending the conference inviting participation in the experiment. Instructions printed on the response sheet indicated that the investigators were interested in the function of alarm sounds generated by common monitors and machines used in the operating room. The subjects were instructed to put on the headphones, start the tape, and rate each of the ten sounds on a scale from 1 ("Not urgent at all") to 7 ("Extremely urgent"), without attempting to identify it, according to the following directions:

Listen carefully to the following ten sounds, which were all recorded from monitors and machines in an operating room. Rate each of them on the scale below for their degree of URGENCY, and circle the appropriate number. In other words, does the alarm sound like it is signalling an urgent, important, or dangerous condition, or does it sound less important for information only)?

In section 2, the subjects were informed that the same sounds would be played in a different order and that they were to identify which of nine possible monitors listed had produced each individual sound. Some types of monitors might appear more than once in the list (e.g., as made by different manufacturers). Finally, they were asked to provide some biographical information, including the presence of any degree of hearing loss.

In order to provide an independent measure of clinical urgency for the alarms, letters were sent to 12 senior anaesthetists (Canadian university department heads) explaining the interest of the investigators in auditory warnings of hospital monitors. Each letter contained a list 


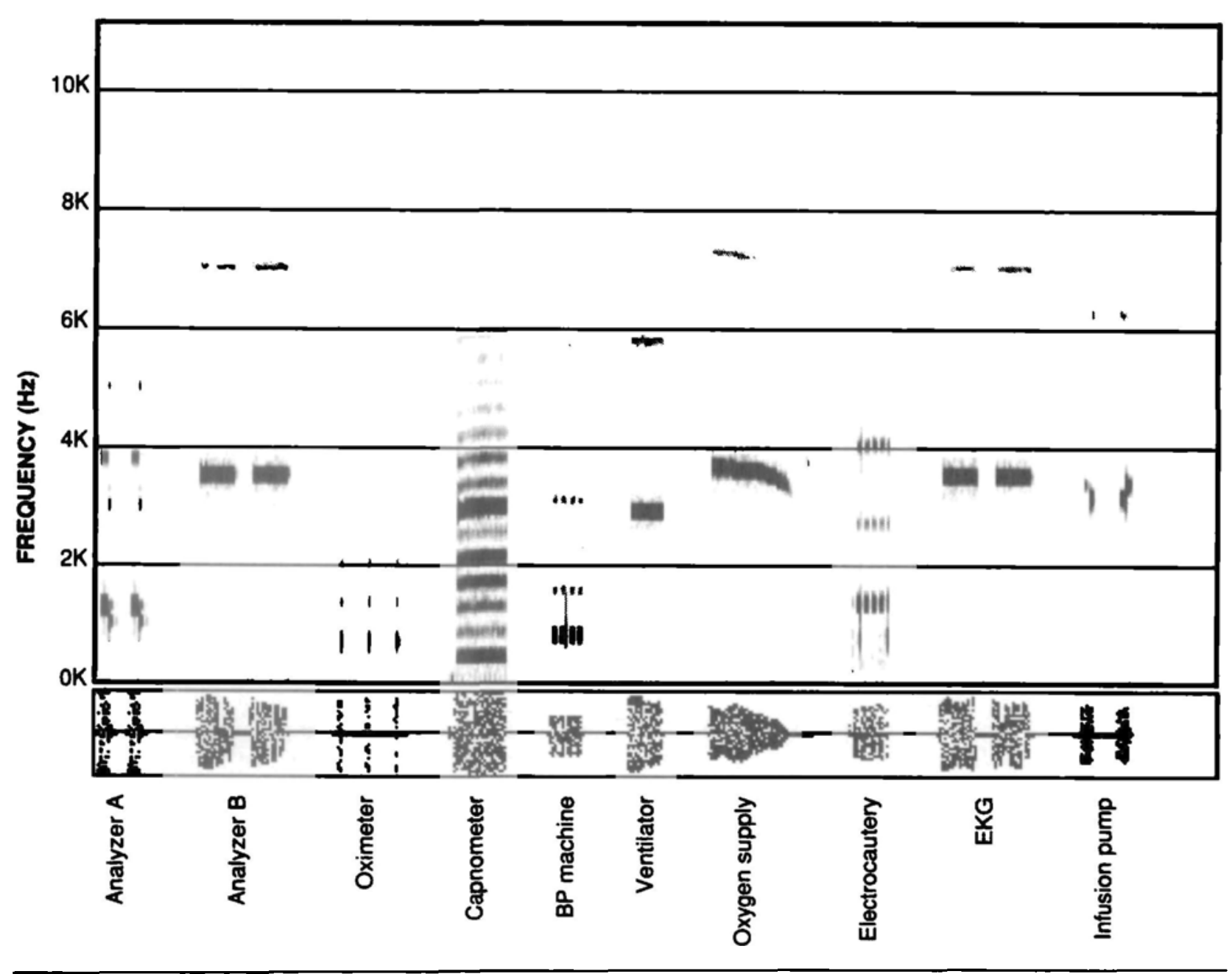

FIGURE Representation of the acoustical signals of the ten alarms each presented for approximately two seconds. The large rectangle on top shows the spectral representation with all frequency components present from 0 to $10 \mathrm{kHz}$. Darker shading indicates a louder signal at that frequency. The narrow rectangle on the bottom shows the envelope of each alarm in terms of overall amplitude as a function of time.

of nine situations that would trigger the auditory wamings of certain monitors. The members of this "expert panel" were asked to rate each of these situations on an urgency scale from 1 ("Not urgent at all") to 7 ("Extremely urgent"), with the following directions:

Please rate each of the following alarms for their degree of URGENCY, and circle the appropriate number on the scale below. In other words, is this clinical situation an urgent, important, or dangerous situation, or is it less important (should the alarm signal indicate "for information only")? If two or three were to go off simultaneously, which would you deal with first? Answer only with reference to the clinical situation suggested, not in connection with any particular alarms you may be familiar with.

The alarm situations were described as follows: "oxy- gen analyzer (low limit); pulse oximeter (pulse signal only, not the alarm); capnograph (apnoea); automatic BP cuff (low limit); ventilator disconnect (low peak pressure); oxygen supply pressure; electrocautery return fault; ECG (low heart rate); infusion pump (air in line)."

\section{Analysis}

For each of the monitors, the medians of the urgency ratings for the subjects and for the expert panel were obtained (Table II), a combined grand median was calculated, and a non-parametric median test 5.6 of the difference between the subjects and the expert panel was carried out. The Chi-square values are shown. The medians for the expert and the subject groups were also compared using Kendall's Rank Correlation Coefficient $(\tau)^{7}$ (Statview SE + Graphics, Abacus Concepts, 1984 Bonita Ave., Berkeley, CA 94704). 
TABLE II Urgency of alarms

\begin{tabular}{|c|c|c|c|c|}
\hline \multirow[b]{2}{*}{ Monitor } & \multicolumn{2}{|l|}{ Medians } & \multirow[b]{2}{*}{$x^{2}$} & \multirow[b]{2}{*}{$P$} \\
\hline & $\begin{array}{l}\text { Experts } \\
\text { ("clinical } \\
\text { urgency") }\end{array}$ & $\begin{array}{l}\text { Anaesthetists } \\
\text { ("perceived } \\
\text { urgency") }\end{array}$ & & \\
\hline Oxygen analyzer $\mathbf{A}$ & 6 & 3 & 11.62 & 0.0007 \\
\hline Oxygen analyzer B & 6 & 5 & 1.84 & 0.1746 \\
\hline Capnometcr & 6 & 6 & 1.28 & 0.2587 \\
\hline BP machine & 4 & 5 & 3.87 & 0.0492 \\
\hline Ventilator disconnect & 7 & 6 & (not tested) & \\
\hline Oxygen supply failure & 6.5 & 6 & 0.22 & 0.6419 \\
\hline Electrocautery & 3 & 6 & 17.81 & 0.0000 \\
\hline ECG & 5 & 6 & 10.37 & 0.0013 \\
\hline Infusion pump & 4 & 4 & 0.04 & 0.8471 \\
\hline
\end{tabular}

Kendall's Rank Correlation Coefficient (corrected for ties): $\tau=-0.034 ; Z=-0.128 ; P=0.8984$.

TABLE III Identification scores

\begin{tabular}{|c|c|c|c|c|c|c|c|c|c|c|}
\hline \multirow[b]{2}{*}{ Response } & \multicolumn{10}{|l|}{ Sound } \\
\hline & $\begin{array}{l}\text { Analyzer } \\
\text { [A] }\end{array}$ & $\begin{array}{l}\text { Analyzer } \\
\text { (B) }\end{array}$ & Oximeter & $\begin{array}{l}\text { Cap- } \\
\text { nometer }\end{array}$ & $\begin{array}{l}B P \\
\text { machine }\end{array}$ & $\begin{array}{l}\text { Venti- } \\
\text { lator }\end{array}$ & $\begin{array}{l}\text { Oxygen } \\
\text { supply }\end{array}$ & $\begin{array}{l}\text { Electro- } \\
\text { cautery }\end{array}$ & $E C G$ & $\begin{array}{l}\text { Infusion } \\
\text { pump }\end{array}$ \\
\hline Oxygen analyzer & 10 & 15 & 1 & 4 & 7 & 11 & 0 & I & 9 & 4 \\
\hline Oximeter & 5 & 10 & 22 & 1 & 9 & 2 & 2 & 3 & 2 & 4 \\
\hline Capnometer & 6 & 6 & 1 & 9 & 5 & 5 & 0 & 5 & 5 & 3 \\
\hline BP machine & 11 & 2 & 1 & 4 & 18 & 2 & 0 & 7 & 0 & 2 \\
\hline Ventilator & 6 & 8 & 0 & 14 & 5 & 28 & 4 & 16 & 18 & 8 \\
\hline Oxygen supply & 1 & 1 & 2 & 9 & 0 & 5 & 54 & 0 & 11 & 0 \\
\hline Electrocautery & 3 & 1 & 0 & 14 & 11 & 1 & 1 & 14 & 3 & 1 \\
\hline ECG & 0 & 2 & 34 & 4 & 1 & 2 & 0 & 11 & 2 & 0 \\
\hline Infusion pump & 14 & 8 & 1 & $\mathbf{I}$ & 3 & 1 & 1 & 1 & 3 & 39 \\
\hline$\%$ Correcl (out of 64) & 15.6 & 23.4 & 34.4 & 14.1 & 28.1 & 43.8 & 84.4 & 21.9 & 3.1 & 60.9 \\
\hline
\end{tabular}

Overall correct scorc $=33.0 \%$

Identification scores were tabulated as the number of correct identifications of each monitor (Table III). The percentage correct was calculated with a denominator equal to the number of participants in that arm of the trial (64).

\section{Results}

Seventy-two anaesthetists took part in the trial, but the data from eight were eliminated due to known hearing loss. The remaining 64 subjects were from 28 cities in Canada, the United States, Great Britain, and the West Indies. Forty-nine were male, and the average age was 40 yr (range 28-65), with an average operating room experience of $11 \mathrm{yr}$ (range 1-28) including residency.

The recording of the alarm from the pulse oximeter was inadvertently truncated, so that the subjects heard only the "beep" of the pulse signal, and not the continuous tone of the alarm itself. The evaluation of perceived urgency is therefore not relevant for that item and is not reported.

The results of the perceived urgency test are presented in Table II. Oxygen analyzer A, blood pressure machine, electrocautery, and ECG show significant differences between the perceived urgency and the urgency of the clinical situation as evaluated by the expert panel. The median test could not be performed on the results for the ventilator disconnect alarm, as all the scores for both groups were equal to or less than the combined grand median (7.0). Kendall's $\tau$ was equal to -0.034 , indicating no significant correlation between the experts' assessment of the urgency of the situation and the anaesthetists' rating of the perceived urgency of the alarm.

The anaesthetists tested were able to identify correctly the monitor alarm sounds only $33 \%$ of the time (Table III). Only two sounds were correctly identified by more 
than $50 \%$ of the participants, the oxygen supply failure alarm (84.4\%) and the infusion pump (60.9\%).

\section{Discussion}

The perceived urgency of an auditory warning can be modified by various acoustical variables. In a number of studies, Patterson, Edworthy, and others have suggested that higher pitch, change in pitch, increased complexity of the harmonic series, increased number or speed of repetitions, and change in speed of repetitions, among other factors, will each increase perceived urgency of the signal in a consistent and predictable way, although the effects of combinations of these factors have not yet been resolved. ${ }^{8-10}$ Some of these variables, such as pitch or loudness, will also increase aversiveness if set too high.

The relationship between the perceived urgency of an alarm signal and the clinical urgency of the situation it indicates has been described by Momtahan and Tansley as "urgency mapping." "It is a critically important feature of good alarm design, as it permits the anaesthetist to assign a priority to each alarm as it occurs and deal with the most important clinical situations first. The lack of urgency mapping in common auditory alarm signals is evident from our results. Of the eight alarm sound trials amenable to statistical test, four showed significant differences between the anaesthetists' scores and those of the expert panel. This was most apparent with the electrocautery alarm, which showed the greatest disparity between perceived and clinical urgency. This finding is of particular interest, as this auditory alarm has little clinical relevance. It identifies that the patient is not correctly grounded to the cautery machine, and therefore frequently sounds at or near the time of anaesthetic induction, but a simple relay to disable the machine, and a visual alarm such as a flashing light, would be adequate and less confusing for the operating room staff. The ECG and blood pressure machines also generated signals that sounded more urgent than the clinical situation would justify. Oxygen analyzer $A$ had a perceived urgency that was less than the urgency of the clinical situation. This should not necessarily be interpreted to mean that this alarm is unsatisfactory and requires modification, as we believe that the most of the other alarm sounds are too aversive.

We assessed perceived urgency using an ordinal scale with specific anchor points in a manner analogous to that used for clinical assessment of pain. Although the validity of the anchor points has not been confirmed, the participants in both groups used most of the scale, suggesting that it was used properly. In addition, rank-ordering of the medians showed even poorer correlation between perceived and clinical urgency.

The results of the perceived urgency component of the study might be criticized on the basis that the subjects' identification of the alarm sound modified their response to the urgency of the alarm. This criticism may, in fact, apply to the two alarms that were identified frequently, but not to the others.

It has been found that most people can remember only five or six alarm sounds consistently, ${ }^{12}$ yet the operating room usually contains many more alerting signals, including alternative (and acoustically unrelated) alarms from patient monitors, as well as signals from pocket pagers, electrical isolation monitors, electrocautery machines, etc. In addition, there is little or no consistency between monitors of different manufacturers that perform the same function. Our results indicate a distressingly poor level of recognition for operating room monitor alarms. Only two alarms were identified correctly by more than $50 \%$ of the subjects. The intravenous infusion pump has a structured or "musical" alarm which, although not standard, is at least more similar to other brands of infusion pump than it is to the other monitors listed. The most impressive result, however, was for the oxygen supply failure alarm, which has a mechanically-generated whistle with a characteristic decay in both pitch and amplitude. This has the virtue of being almost universal on Canadian anaesthetic machines, as it is required for Canadian Standards Association certification. ${ }^{13}$ Clearly, it is possible to set standards that result in similar sounds for the same alarm on different machines, which would avoid the current confusing situation of different alarms meaning the same thing, or the same alarm meaning different things, in different operating rooms (consider the consequences of a green traffic light indicating "go" in one city and "stop" in another). Although our subjects came from a variety of hospitals in different cities, and thus might have considerably different experience, similar studies by Momtahan and Tansley" and by Loeb et al. ${ }^{14}$ of anaesthetists at a single hospital showed similar or lower rates of correct identification.

Examination of the sonograms (Figure) provides an explanation for some of the problems with the current auditory alarms. Many of the sounds (ECG, oxygen analyzer B, ventilator disconnect, oximeter) are similar, high-pitched, continuous or regularly spaced signals that are irritating and difficult to identify. The presence of only a few harmonics prevents easy localization of the sound in space and increases the risk of masking of the sound by other alarms or noises. ${ }^{8,10}$ On the other hand, the sonogram for the capnometer shows a complex harmonic structure which should be easier to identify, difficult to mask, and extremely urgent. Unfortunately, this particular alarm also comes on at full volume (with no volume control) and is continuous. It is, therefore, intrusive, irritating, and likely to be disabled by the anaesthetist. 
The musical patterns of the infusion pump and oxygen analyzer $\mathrm{A}$ alarms are less irritating, and should be easy to identify. The low identification score for oxygen analyzer $A$ in our study was probably due to the relative rarity of that particular model at that time, and to the fact that the manufacturer uses a similar sound for many of its warnings, relying on visual cues to distinguish between them.

Our results support the contention that many of the current auditory alarms in clinical use are poorly designed. A number of attempts have been made to design auditory alarm systems for hospital use which are easy to remember, non-aversive, and predictable with respect to perceived urgency. ${ }^{8.15} \mathrm{~A}$ few individual manufacturers are developing their own integrated alarm systems which present patient and machine alarms in order of predetermined level of importance, although we are aware of only one paper that describes the philosophy behind such a design. ${ }^{16}$ This type of system is still not easily compatible with the equipment of other manufacturers, even though it is unreasonable, in the current economic climate, to expect any hospital to equip a complete operating suite at one time with the equipment of a single manufacturer. In any case, there is little evidence that these proposed systems have undergone clinical evaluation.

The International Standards Organization has prepared a draft proposal of alarm signals specifications, ${ }^{17}$ and several national standards organizations have addressed the problem. Recognizing the need for further research before variables can be defined for specific alarms, the American Society for Testing and Materials has a draft standard in development which defines minimum acoustical criteria for hospital alarms. ${ }^{18}$ These are designed to reduce the aversive quality of alarms without restricting future research. The fundamental frequency is limited to the range of 150 to $1000 \mathrm{~Hz}$, with at least four frequency components between 300 and $4000 \mathrm{~Hz}$ and a maximum sound intensity of $85 \mathrm{~dB}(\mathrm{~A})$. In addition, the standard provides some guidance as to the principles of alarm design which govern perceived urgency.

Improved identifiability of alarms has not been studied in the operating room environment. A number of approaches has been suggested, including voice synthesis and the use of auditory icons. ${ }^{19}$ Training of the anaesthetist and pre-audition might also improve performance. All of these techniques would be amenable to clinical or experimental study.

In conclusion, we have demonstrated that there is poor correlation between the perceived and clinical urgency of some common operating room monitor alarms, and that practicing anaesthetists cannot identify most of them. In addition to further extensive research in the ergonomic factors required for good alarm design, we feel that greater "consumer awareness" is required. Formal elaboration of standards must follow a better understanding of the principles involved, and must respond to consumer demand. Manufacturers and designers will respond more enthusiastically to requests from practising anaesthetists than to government legislation, and it is time for manufacturers to be prepared to defend the design and functional effectiveness of their alarm systems in the actual working environment of the operating room, rather than adding more bells and whistles to attract attention in the showroom.

\section{Acknowledgements}

The authors would like to thank the following: Ann Andrews, Executive Director of the Canadian Anaesthetists' Society, for her patience and support at the time of the Annual Meeting in Halifax; Shawn Currie, Carolyn McDiarmid, Philip Gagnon, and Michael Lamoureux $\mathrm{PhD}$; Dr. J.D. Morrison, for many valuable suggestions during the preparation of the manuscript; and Dr. John Muir, for precipitating us into this area of research.

This study was supported in part by grants from Glaxo Canada Inc. (GAF) and the Natural Sciences and Engineering Research Council of Canada (AJC).

These results were presented in part at the Annual Meeting of the Canadian Acoustical Association in Halifax, October 18, 1989.

\section{References}

1 Sorkin RD, Woods DD. Systems with human monitors: a signal detection analysis. Human-Computer Interaction 1985; 1: 49-75.

2 Mclntyre JWR. Ergonomics: anaesthetists' use of auditory alarms in the operating room. Int $\mathrm{J}$ Clin Monit Comput 1985; 2: 47-55.

3 Sorkin $R D$. Why are people turning off our alarms? J Acoust Soc Am 1988; 84: 1107-8.

4 Kestin IG, Miller BR, Lockhart $C H$. Auditory alarms during anesthesia monitoring. Anesthesiology 1988; 69: 106-9.

5 Seigel S. Non-parametric Statistics for the Behavioral Sciences. McGraw-Hill, New York, NY, 1956; 55.

6 SPSS-X User's Guide, 3rd Ed. SPSS Inc. Chicago, 1988; 738.

7 Sokal RR, Rohlf FJ. Biometry - The Principles and Practice of Statistics in Biological Research. W. H. Freeman, San Francisco, 1969; 533.

8 Patterson RD, Edworthy J, Shailer MJ, Lower MC, Wheeler $P D$. Alarm sounds for medical equipment in intensive care areas and operating theatres. Institute of Sound and Vibration Research Report AC598, University of Southampton, 1986. 
9 Hellier E, Edworthy J. Quantifying the perceived urgency of auditory warnings. Canadian Acoustics 1989; 17: 3-11.

10 Momtahan KL. Mapping of psychoacoustic parameters to the perceived urgency of auditory warning signals.

M.A. Thesis (Psychology), Carleton University, 1990.

11 Momtahan $K L$, Tansley $B W$. An ergonomic analysis of the auditory alarm signals in the operating room and recovery room. Proceedings of the Annual Meeting of the Canadian Acoustical Association, Halifax, October 18, $1989 ; 140$.

12 Patterson $R D$, Milroy $R$. Auditory warnings on civil aircraft: the learning and retention of warnings. Civil Aviation Authority Paper 7D/S/0142, London, 1980.

13 Continuous flow inhalation anaesthetic apparatus (anaesthetic machines) for medical use. CSA Standard Z168.3-M1980, clause 14.2.2. Canadian Standards Association, Rexdale, Ontario; 1980.

14 Loeb RC, Jones BR, Behrman KH, Leonard RJ. Anesthetists cannot identify audible alarms. Anesthesiology 1990; 73: A539.

15 Stanford LM, Mclntyre JWR, Nelson TM, Hogan JT. Affective responses to commercial and experimental auditory alarm signals for anaesthesia delivery and physiological monitoring equipment. Int J Clin Monit Comput 1988; 5: 111-8.

16 Schreiber PJ, Schreiber J. Structured alarm systems for the operating room. J Clin Monit 1989; 5: 201-4.

17 Specification for alarm signals used in anaesthesia and critical care. ISO/TC 12l/SC 3 N687. International Standards Organization, Helsinki, 1987.

18 Specifications for alarm signals in medical equipment used in anesthesia and respiratory care (draft). Amcrican Society for Testing and Materials (Subcommittee F29.03.04 - Harmonization of Alarms), Philadelphia, 1991.

19 Gaver WW. Auditory icons: using sound in computer interfaces. Human-Computer Interaction 1986; 2: 167-77. 